\title{
WHAT A MAN WANTS, WHAT A MAN NEEDS: MARKERS OF MASCULINITY IN PRINT ADVERTISING
}

\author{
Lars M. BLÖHDORN, Sabrina MEYN-KRUSE, Nadja LINKE \\ Kiel University, Germany
}

\begin{abstract}
Which advertisements appeal to a male readership? What are the underlying strategies used to target men? With the help of a corpus of adjectives derived from the men's magazine $G Q$, this study seeks to analyze how masculinity is constructed in print advertising. In doing so, it approaches the phenomenon of 'male language' from a sociolinguistic perspective focused on gender and employs quantitative as well as qualitative evaluation methods to reveal that current advertising campaigns construct 'male lifestyles' around products by using adjectives that convey simplistic and straight-forward messages, but also go beyond that by taking into account non-linear approaches when targeting a male audience. Finally, a comparison with advertisements in the women's magazine Cosmopolitan highlights the emergence of gender-specific features as well as gender-oriented product groups and reveals categories and concepts that are exclusive to their target genders.
\end{abstract}

Keywords: advertisement; adjectives; corpus linguistics; sociolinguistic perspective; gender; differences; GQ; Cosmopolitan.

\section{INTRODUCTION}

"Don't crack under pressure." "Delicious dressed up or naked." Advertisement slogans that contain language such as this stick to people's minds. Meyn, Schröder, and Verthein (2015) found out that comparable slogans in advertisements directed at women in the magazine Cosmopolitan persuade women into buying the

LiNGUACULTURE vol. 12 , no. 1,2021

Published: 15 June 2021

DOI: 10.4773 /lincu-2021-1-0192

ISSN (print): 2067-9696 || ISSN (online): 2285-9403 || www.journal.linguaculture.ro 
respective products. While some of the results highlighted a number of emotional and creative approaches, they simultaneously raised the question of whether advertisements directed at men address their readers in a similar fashion. Since the focus of the aforementioned study lay on the analysis of women's magazines, however, it ultimately became evident that a study which focuses exclusively on the male perspective would be needed to further explore this topic.

The study at hand seeks to bridge this gap by conducting an in-depth analysis of print advertisements in the US-American men's magazine $G Q$. One of the aims is to identify the ways in which advertisements appeal to their male readership. Moreover, it wants to explore what the underlying strategies used to target men entail. Hence, in a first step, it needs to be analyzed how masculinity is constructed within those advertisements. This is achieved through the compilation of a corpus of adjectives derived from the above-mentioned men's magazine $G Q$. Adjectives, as "the key parts of speech for advertisers," are able to trigger "envy, dreams and desires by evoking looks, touch, taste, smell and sounds" (Dyer 149). Consequently, adjectives serve as a fruitful source to determine how the needs of men are generated through the language of advertising. Moreover, the collection of adjectives allows for conclusions with regard to linguistic advertisement strategies and their goals in a second step. In order to create the corpus, all adjectives from the advertisements distributed in the selected issues of $G Q$ Magazine were extracted and collected in tabular form. The adjectives were then placed into categories according to Huddleston and Pullum (2005) in order to draw conclusions about underlying strategies.

This paper approaches the phenomenon of 'male language' from a select sociolinguistic perspective, taking into account that it concentrates on a correlation of language and gender (cf. Coates 2016). The 2016 issues of the USAmerican $G Q$, whose editors describe it as the "premier men's magazine," were singled out as a prime object of investigation because the publisher claims that "millions of leading men" read the magazine each month ${ }^{1}$. Three guiding questions are in the focus of the present research:

(1) Which specific strategies are used in GQ Magazine advertisements?

(2) How are the strategies reflected in the use of adjectives?

(3) Are men and women addressed in different ways by the use of adjectives?

In order to answer these research questions, the study employs a mixed-method design (cf. Hesse-Biber 2010) which makes use of quantitative as well as qualitative evaluation methods. In a first step, a frequency analysis of advertised products and their market segment is carried out. In a second step, advertisements

\footnotetext{
${ }^{1} \mathrm{http} / / / \mathrm{www} . c o n d e n a s t . c o m / \mathrm{brands} / \mathrm{gq} /$ (accessed on 05/08/2017).
} 
are analyzed according to the qualitative content analysis foremost employed in social studies (cf. Mayring 2010). The method ensures a detailed analysis of the material on a semantic and linguistic level. For this, the aforementioned adjective corpus will be created. Regarding the third research question, the findings of this research will be put into context to the research by Meyn, Schröder and Verthein (2015).

\section{IS ADVERTISING NECESSARY?}

This research is concerned with 'commercial consumer advertising.' According to Vestergaard and Schrøder (1f), this is the most visible and frequent type of advertising and involves "a firm appealing to individual private consumers." Furthermore, Dyer (4) emphasizes that this kind of advertising "commands more expenditure, space and professional skill than any other type and is directed towards a mass audience." Vestergaard and Schrøder, (1) continue that commercial consumer advertising is "the type on which most money and skill is spent, and the type that affects us most deeply." Harris and Seldon (40) provide a definition of the phenomenon. They explain that commercial consumer advertising "is designed to spread information with a view to promoting the sales of marketable goods and services."

Vestergaard and Schrøder (3) ask two interesting questions about advertising:

(4) Is advertising necessary?

(5) Why does it have to be persuasive?

Their answers are based on the living conditions of people by suggesting that as soon as people "live above subsistence level [...] it also becomes necessary for the producers of materially 'unnecessary' goods to do something to make the people want to acquire their commodities." The reason why modern advertising established to be persuasive is also illustrated by Vestergaard and Schrøder (4). The development of technology and mass production techniques in the late $19^{\text {th }}$ century led to "overproduction and underdemand so advertising technique changed from proclamation to persuasion." This constituted a major shift in the advertising industry. This shift is characterized by a highly creative effort. Due to the overproduction, the market had to come up with strategies to stay competitive. This resulted in the creation of persuasive and creative strategies which will be the focus of the next section. 


\section{SELECTED ADVERTISING STRATEGIES}

Katz (36f) emphasizes that advertisers have to be able to create a need for their products. However, not only creating this need, but "defining what this need might be" (Katz 37) is crucial when advertisers go about their business to think up language which serves this purpose. Linguistically, adjectives are the first and foremost word class which is able to define qualities. Adjectives "typically denote properties which modify referents such as objects, persons, places, and so forth" (Blöhdorn 25). Applied to the topic of advertising, adjectives denote those properties of the advertised products which influence the potential consumers. Thus, using adjectives to create and define a need in advertising is one fundamental strategy in marketing. Dyer (149) even goes so far as to define adjectives as the "key parts of speech for advertisers [...] because they can stimulate envy, dreams, and desires by evoking looks, touch, taste, smell, and sounds without actually misinterpreting a product." Consequently, the use of adjectives as trigger words to generate needs is an essential strategy in advertising and, thus, in the focus of this research.

First, advertisers want to give the potential consumer a positive perspective. Sternkopf (209) highlights that the selling power of an advertisement is increased through positivity. Accordingly, "prohibitions and negative forms are usually avoided, [however] adjectives with a positive meaning play a major role in advertising language" (209). As a conclusion, a major strategy with regard to the use of adjectives in advertising is the avoidance of negativity and the use of positive adjectives in order to give the recipients a positive outlook.

Example (6) lists several adjectives which Leech (14) claims to be frequently used adjectives at the time of publication - they illustrate how advertisers apparently seek to spread positivity through their ads.

(6) new, good, fresh, delicious, full, sure, clean, wonderful, special

In addition to the advertisers' leitmotiv to 'stay positive,' another significant advertising strategy is connected to a core human need: the need for selfexpression. Belk (2000: 76) recognizes the following: "We are what we have and possess. This is perhaps the most basic and powerful fact of consumer behavior." "[P]ossessions," he continues, are treated "as extensions of ourselves." Ingwer (75) also highlights the importance of self-expression by emphasizing that "without the means to show off or communicate who we are, we have no way of conveying to ourselves and others that we're even relevant or alive!" Thus, people need modes of self-expression to be able to "confirm [ourselves] of our individual worth" (Ingwer 2012: 75). 
What are these modes of self-expression? Besides our words and thoughts, possessions are a dominant mode of self-expression (cf. Ingwer 2014). Advertisers use this knowledge as a powerful tool. Accordingly, they do not seek to sell the mere products any longer, but they want to sell a 'consumer lifestyle' (Ingwer 2014). By attaching a lifestyle to the advertised product, they want it to "fit in with who they [the consumers] are and who they hope to become" (Ingwer 2014). Kornberger (2010) determines this strategy of 'selling a lifestyle' as one of the "master concepts" in advertising:

Rather than persuading people that certain brands [products] fit into their lives, the concept of lifestyle turns this reactive logic around. From now on, branding [advertising] would be about defining lifestyles and then, proactively, selling products into the newly stylized context. (Kornberger 191)

Selling a lifestyle also includes customizing it for specific target audiences. Thus, lifestyle research helps advertisers to "understand how a product fits into consumers' general behavior patterns" by analyzing consumers' activities, interests, and opinions (Hoyer/MacInnis/Pieters 391). This analysis is naturally connected to demographics such as gender, age, education, or geography (cf. Hoyer/ MacInnis/ Pieters 392).

In conclusion, advertisers do not only sell products but consumer lifestyles into which their product is embedded. Nevertheless, besides the three major strategies of 'using adjectives as trigger words,' 'positivity,' and 'selling a consumer lifestyle,' another persuasion technique represents an additional vital approach for advertisers.

This approach is based on gender research and must be considered by advertisers when the target group comprises male consumers. To explore this strategy, differences between male and female language will be contemplated in the following. It is no secret that men and women differ in the way they talk and communicate. These differences are also reflected in the perception of male or female talk: men's speech is referred to as "more confident, militant, authoritarian" (Swann 16) - so getting straight to the point - as opposed to women, whose speech is described as "gentle, and smooth; [...] friendly, [...] enthusiastic and emotional" (Swann 16), giving many details while they talk. These linguistic gender differences originate from our society, which tends to spread genderspecific roles and therefore pushes men and women into their specific behavior patterns. Moreover, family, friends, and society ensure that girls and boys, from birth onward, learn how to behave appropriately according to their gender. These differences are not only prominently reflected in spoken language, but also in written language (Swann 1ff.) 
Besides these linguistic differences, Sheehan (2014) suggests that advertisers are also interested in how men and women differ in the way they receive and evaluate information. Whereas "men look directly at the primary message of a given advertisement, [w]omen not only evaluate the primary message of a given advertisement, but they also [...] intuit and infer the inner meaning of the message" (Sheehan 90). This way of processing an advertisement can be traced to the way in which men and women process information: "[M]en have a linear thinking and reasoning style, and men tend to have a more taskoriented focus [...]. Women's reasoning processes are less task-oriented and more compartmentalized than men's are" (90). What does this, in turn, mean for advertisers? Based on the way men talk (confident, getting straight to the point) and the way they deal with information and advertisements respectively, it can be deduced that advertisers should use language which gets straight to the point and can be directly processed. In conclusion, the theory implies that advertising language should be characterized by clarity and conciseness.

Concluding, apart from the use of adjectives as trigger words in advertising, three major strategies which are significant when addressing male audiences were identified. These are listed in (7) through (9):

(7) using positively connoted languages

(8) selling a consumer lifestyle

(9) providing a clear and concise message

To explore how advertisers try to persuade women, the next section will briefly recapitulate the findings of the previously mentioned study by Meyn, Schröder, and Verthein (2015).

\section{WHAT A WOMAN WANTS}

In their study, Meyn, Schröder, and Verthein (2015) looked at "female advertising language in the woman's magazine Cosmopolitan [...] by presenting an extensive corpus analysis of the use of adjectives within this specific magazine: the Cosmopolitan Adjective Corpus" (Meyn/Schröder/Verthein 47). This corpus was compiled of Cosmopolitan advertisements from February 2013 to January 2014 and provided answers on how women are persuaded by advertisements which are directed at a predominantly female audience. Three major results were extracted: First and foremost, "the deliberate evocation of emotions via abstract color neologisms" (Meyn/Schröder/ Verthein 65). The study revealed that "advertisers try to attach specific feelings to their products" (Meyn/Schröder/Verthein 61). 
Examples (10) through (12) demonstrate how the advertisers connect emotional associations to their products:

(10) First Date at the Golden Gate

(11) Kiss Me at Midnight

(12) Sleigh Ride for Two

(Meyn/Schröder/Verthein 61)

Secondly, a considerable number of adjectives (12.6\%) referred to effects on the potential consumer. Hence, quality adjectives which describe what kind of effects the advertised products have on the addressee are used to attract potential consumers. Apart from adjectives that describe the quality of the product itself, advertisers use adjectives to describe effects of a product on the consumer. This is reflected in examples (13) through (15):

(13) beautiful

(14) chic

(15) happy

(Meyn/Schröder/Verthein 55)

Thirdly and lastly, the study of Cosmopolitan advertisements revealed that the construction of identity plays a significant role for advertisers who want to attract the attention of women. To be precise, advertisers use the concept of beauty to provoke a signification process. In the twelve issues of Cosmopolitan, "67 percent of the advertisements aim at the outer appearance of the customers; this places the focus on the imperfection of the body, and thus the need to change its appearance" (Meyn/Schröder/Verthein 61). In this fashion, advertisers want to make the consumer believe that an ideal identity can only be constructed by using their products. Two findings in the adjective corpus contributed to the validation of this strategy. On the one hand, a considerable number of adjectives $(28.3 \%)$ describe the quality of the products, highlighting that the product is essential for the construction of identity. Amongst others, examples (16) and (17) substantiate this claim:

(16) brilliant

(17) exclusive

(Meyn/Schröder/Verthein 55) 
On the other hand, adjectives are used to promote the opposite of their literal meaning $(5.2 \%)$, not only laying the focus on the imperfection, but also naming it. Consider examples (18) and (19):

(18) dry

(19) greasy

(Meyn/Schröder/Verthein 55)

In summary, the attachment of emotions to the product, the use of adjectives that refer directly to the addressee and the focus on the imperfection of the consumer's bodies were major findings in the study of Cosmopolitan advertisements. In the next section, the results of both studies will be put into comparison.

\section{THE USE OF ADJECTIVES IN GQ ADVERTISEMENTS}

To explore in which way advertising strategies which target men make use of adjectives, the study at hand took twelve issues of the lifestyle magazine $G Q$ as the basis of its analysis. A first result was the creation of the ' $G Q$ Adjective Corpus' - a careful compilation of all advertisements which contain adjectives. The corpus includes the total number of adjectives (755) and advertisements (564) plus the number of advertisements with adjectives (195) or without adjectives (369) and lastly the advertised type of products (cf. Figure 1).

The adjectives were then classified into nine different categories based on the research of Meyn/Schröder/Verthein (2015), who established adjective categories according to prototypical properties of adjectives: age, size, shape and weight, color, merit, and quality (cf. Huddelston/Pullum 2005). However, the semantic classification had to be adapted to the present results, because not all the identified adjectives clearly allocated to the categories provided by Huddelston and Pullum (2005). Hence, the classification lead to the ten distinct categories (a) through (j) which will be further explained below:
(a) Related to Time and Age
(b) Size
(c) Shape, Composition, and Weight
(d) Personal Quality
(e) Material Quality
(f) Associative Quality
(g)Color
(h) Negated
(i) Other 


\section{(j) Modifiers}

While most of the categories are self-explanatory, some of the categories need further clarification. The semantic category of 'quality' is divided into three branches. First, adjectives classified as 'personal quality' "refer to a person, hence the addressee of the advertisement in this case, and thus the potential customer" (Meyn/Schröder/Verthein 55). Second, 'material quality' contains adjectives which further qualify the advertised product (cf. Meyn/Schröder/Verthein 55). The third category, 'associative quality,' which was added to the present study, refers to adjectives which trigger associations to a lifestyle constructed by the advertisers. In other words, associative quality adjectives embed the product into a constructed lifestyle, sometimes without any link to the promoted product.

\begin{tabular}{|l|l|}
\hline Category & Examples \\
\hline Related to Time and Age & advanced (5), modern (6), new (52), original (4) \\
\hline Size & big (2),global (1), great (3), less (5), little (3) \\
\hline $\begin{array}{l}\text { Shape, Comp., and } \\
\text { Weight }\end{array}$ & creamy (2), distilled (5), thinnest (1) \\
\hline Personal Quality & better (2), crazy (1), great (2), pretty (3) \\
\hline Material Quality & finest (7), great (12), perfect (10), smooth (8) \\
\hline Associative Quality & pure (2),real (2), stylish (2) \\
\hline Color & $\begin{array}{l}\text { black (2), brighter (1), charcoal grey (1), tortoise } \\
\text { (1), }\end{array}$ \\
\hline Other & certain (2), every (4), simple (2) \\
\hline Modifiers & completely (3), most (12), simply (5), very (2) \\
\hline
\end{tabular}

Table 1: Adjective categories and selected adjectives from the $G Q$ Adjective Corpus.

The 'negated' category contains adjectives "which are used to promote the opposite of their literal meaning" (Meyn/Schröder/Verthein 55). However, the $G Q$ Adjective Corpus does not contain any instances of adjectives of this kind. All the adjectives which could not be clearly assigned to one of the categories above were tagged as belonging to the category of 'other.' With regard to this, it is important to mention that the classification of the adjectives is highly dependent on the individual context, especially in the three 'quality' categories. Table 1 on the previous page presents a small selection of the collected adjectives.

All in all, a total of 564 advertisements of $G Q$ issues from January 2016 to December 2016 were analyzed. Out of the 564 advertisements, 238 promote 'clothing brands.' The second largest category is 'accessories' with 79 instances, followed by 'cosmetic products' (74). Compared to the others, 'food \& drinks' (47) 
as well as 'cars' (45) make up a relatively small amount. Figure gives an overview of all product categories and their percentages.

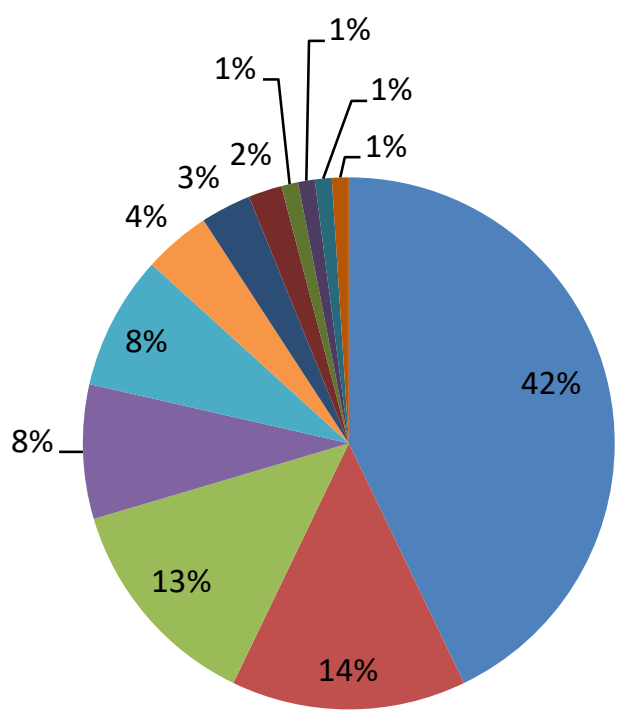

- Clothing

Accessories

Cosmetics

- Cars

- Food\&Drinks

Finances

Electronics

Media

Other

- GQ

$\square \mathrm{TV}$

- Medicine

Figure 1: Categories of advertised products $(G Q)$.

Shifting the focus back on the aspect of adjective use, however, only 195 out of 564 advertisements were linguistically relevant to the research questions presented in Section 1. Despite the smaller amount of advertisements and the redistribution of the product groups, the 'clothing' category remains the most advertised (46). The first changes were noticeable in the case of 'accessories' and 'cosmetics.' Instead of these two, 'food \& drinks' (33) as well as 'cars' (29) are now the second and third largest group.

Figure 2 presents the distribution of all the product categories with adjectives. Summarizing the first findings, only 34.6 percent out of all the extracted advertisements include adjectives. The rest does not feature adjectives nor any editorial text. In the end, 755 adjectives were identified, resulting in an average of 1.3 adjectives per advertisement, which also includes the advertisements which do not contain any adjectives. Adjusted for these instances without adjective appearance, the average of adjectives per ad rises from 1.3 to 3.9 percent. 


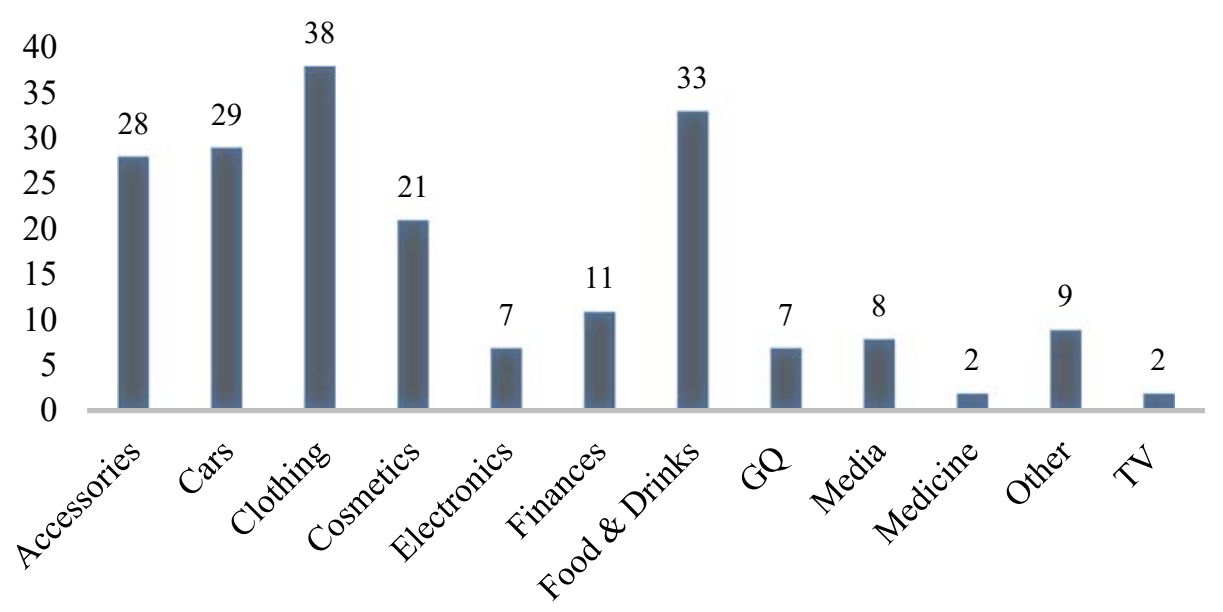

Figure 2: Categories of advertised products $(G Q)$ with adjectives.

As mentioned at the beginning of the section, the adjectives were allocated to nine semantic adjectives categories. For the analysis of the 755 adjectives in the corpus, two sums per category have to be considered. On the one hand, the total number of adjectives per category (tokens) - meaning the number of adjectives regardless of the number of repetitions - and on the other hand, the number of different adjectives per category (types) - or in other words, the number of distinct adjectives. Figure 3 illustrates all of the 755 adjectives in their corresponding categories.

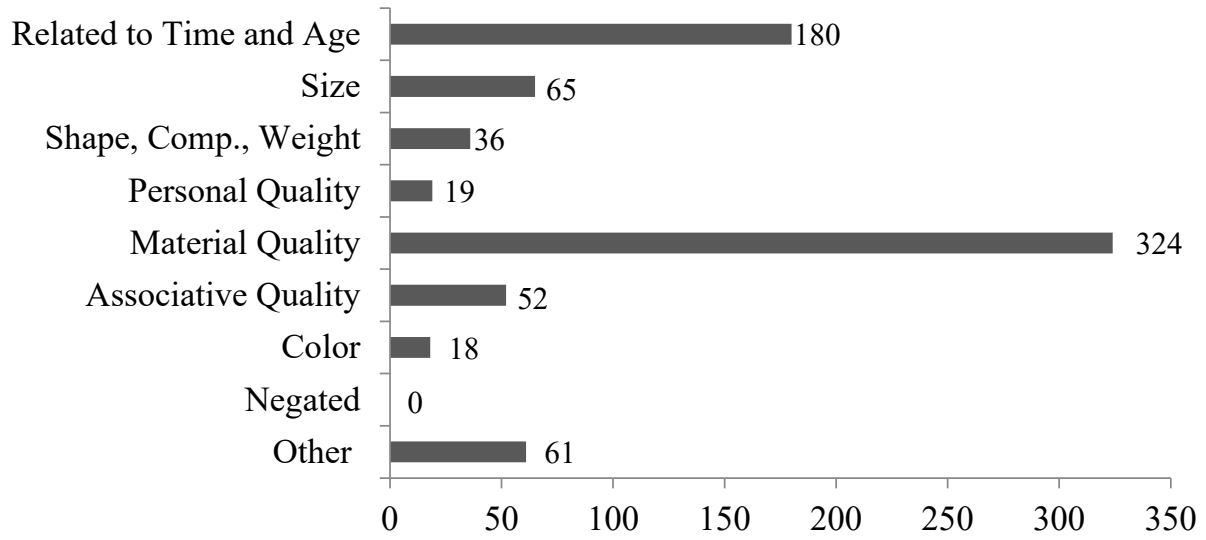

Figure 3: Total number of adjectives per category (tokens). 
With regard to tokens, 'material quality' adjectives are by far the most with a distribution of 324 adjectives, making up 42.9 percent of the total number. Adjectives related to 'time and age' constitute the second largest category, counting 180 adjectives or a share of 23.8 percent. Adjectives which describe 'size' rank third place with 65 adjectives, followed by 'other' with 61 , 'associative quality' with 52, 'shape, composition, and weight' with 36 , 'personal quality' with 19 , and 'color' with 18 adjectives.

Concerning types, the ranking of the adjective categories slightly changes. The most distinct adjectives are provided by the 'material quality' category: 194 adjectives, making up 40.4 percent of the total number. Here, two noteworthy findings should be mentioned. Firstly, the category 'size' does not contain a great variety of adjectives. While there are 65 tokens, the number of types now is almost reduced by 50 percent (cf. Figure 4 ). Nevertheless, 'associative quality' adjectives, which describe a distinct lifestyle, provide a significant variety of adjectives (52 tokens compared to 47 types). A complete overview of the types is presented in Figure 4.

A closer look will now be taken at the most frequently used adjectives. Among the top ten with respect to frequency are: new (52), great (12), perfect (10), best (9), smooth (8), finest (7), better (6), modern (6), first (6), and advanced (5).

As a last step before the actual analysis, it appears relevant to briefly present the documented modifiers. In this context, modifiers are considered to be words that change, qualify, or restrict adjectives (cf. Paradis 1997). A total number of 98 modifiers were identified in the studied issues of $G Q$. Considering tokens, there are 27 distinct modifiers in the Corpus. The modifiers distributed most frequently are most (12), followed by simply (5).

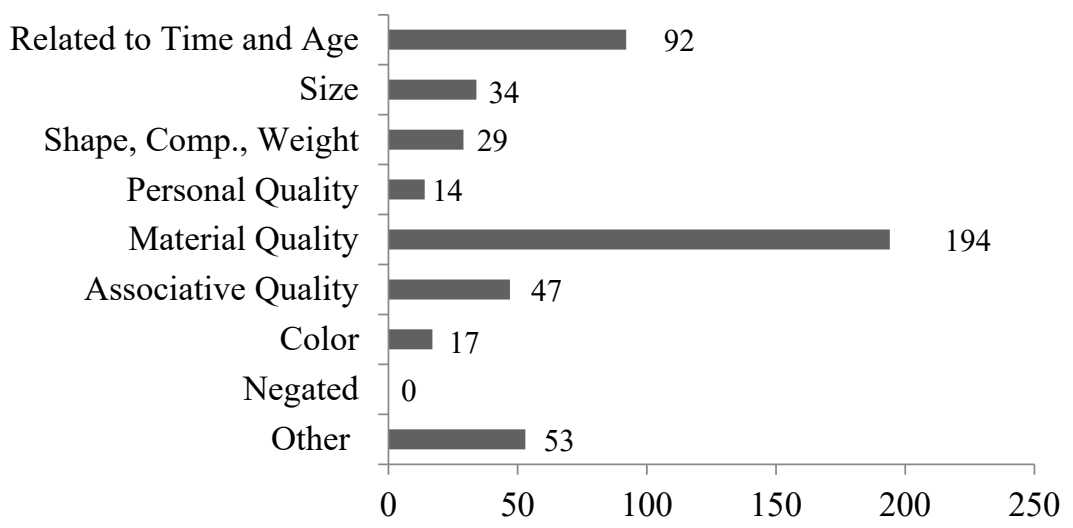

Figure 4: Number of different adjectives per category (types). 
Research question (2) in Section 1 asked whether the theoretical claims about advertising strategies were reflected in the given material. Beginning with the claim that advertisers mostly employ positively connoted language to increase the selling power of products, the following observations can be made. The lack of negated adjectives across all $G Q$ advertisements attests to the thoroughly positive attitude which advertisers want to achieve. Moreover, the employment of mostly intensifying modifiers adds into that nicely and functions as a measure towards establishing a positive mindset for the consumer. Consider examples (20) through (22), which substantiate this claim:

(20) Give the uniquely inspirational style of GQ this holiday season. (GQ Gift)

(21) An all-about-GQ, exclusive online community. Are you in? (GQ Insider)

(21) Cold brewed coffee slow-steeped for 20 hours by your barista for supersmooth flavor. (Starbucks)

Adjectives of the 'material quality' category also foster positive feelings towards the products and their qualities. This is visualized by examples (22) through (24):

(22) You could enjoy satisfying professional service 24/7, from a company that's made it their business to help people since 1936. This winning combination has helped GEICO [...] (Geico)

(23) With daring curves, a commanding race-inspired stance, and handling so responsive it feels like the car is an extension of you. (Infinity)

(24) Pure is in our name - because Isopure Protein means perfect, delicious, $100 \%$ Whey Protein Isolate (Isopure)

Each of the exemplified advertisements deliberately employs adjectives with a positive connotation to persuade the target audience into buying their products. In other words, the examples confirm positivity as an advertising strategy in $G Q$. In addition to the feature of positivity, Ingwer (2014) remarks that selling a lifestyle is another dominant factor in the world of advertising. With respect to the corpus material, the first noticeable aspect is the small amount of 'personal quality adjectives'. Subsequently, compiling facts about users' personal benefits plays a minor role in the persuasion process. Instead, 'associative quality adjectives' which embed the product into a constructed lifestyle - sometimes without any apparent link to the promoted good - are being employed. All the 
adjectives which belong to this category are highly dependent on the context. The following two examples (25) and (26) illustrate the aforementioned phenomena:

(25) Many dads feel the same way: that being a father doesn't mean downgrading from a stylish, self-determined life. [...] "Power Dads" like Wilson navigate the worlds of personal and professional success. (Lexus)

(26) The cool, low-light vibe of Brooklyn's speakeasy-inspired nightlife is perfect for Transitions lenses. (Transition Xtractive)

Example (25) is an advertisement for a new Lexus model in which actor Paul Wilson is used as a testimonial to represent and attract men, fathers in particular. By commenting on his attempts to find a balance between his professional and private life, he aims at making a point that dads can be stylish when driving this specific car.

The same applies to example (26). In the advertisement for Transition Xtractive contact lenses, a CEO serves as a testimonial and retells his daily routine. Through the use of specific adjectives such as speakeasy-inspired, he successfully establishes a connection between the product and a setting with which everybody can either identify or wants to be in. In other words, the advertisement reveals the undisclosed desires of consumers with the help of specific adjectives. The abovementioned examples demonstrate that the strategy of selling a lifestyle is indeed used to attract a male audience.

In her research about contemporary advertising, Sheehan (2014) introduces a postulation about men's information processing: she believes men to be 'linear thinkers' (cf. Sheehan 2014: 90). This is reflected by the need of being presented with point-blank messages in order to be convinced by a product and its benefits. 'Material quality,' the largest adjective category, demonstrates a tendency towards favoring fact-based information, as examples (27) through (29) show:

(27) Skechers with air-cooled memory foam (Skechers)

(28) It requires Mexico's finest 100\% Weber Blue Agave, hand-selected and distilled in custom copper stills for a smooth finish every time. (Silver Patron)

(29) Opening New York Men's Fashion Week, the iconic American designer's 2016 fall/winter collection channeled the high-quality bespoke traditions of Savile Row - rich fabrics, rakish patterns, elegant silhouettes - and added a dose of American ruggedness. (Joseph Abboud) 
However, the idea of men being linear thinkers clashes with Ingwer's (2014) claim of attaching a lifestyle to a product since the latter is not conveyed through factbased information but rather through an emotional appeal as the examples demonstrate. Ultimately, selling a lifestyle is a non-linear approach by evoking emotions and attaching them to a product. As a result, the consumer is bonding with the good on the basis of emotions and not on facts. Therefore, Sheehan's (2014) theory can only partly be confirmed within the scope of this paper. To sum up, the material provided evidence for the employment of all three strategies. In order to answer the third research question, the next section will compare these findings to the main results of the Cosmopolitan study (Meyn/Schröder/Verthein 2015).

\section{GQ VS. COSMOPOLITAN - A COMPARISON}

To explore whether men and women are addressed differently by the use of adjectives in print advertising, this section will compare the findings presented above to the findings of Meyn/Schröder/Verthein (2015), which were introduced in section 4 .

It seems noteworthy that the twelve issues of $G Q$ feature much fewer advertisements than the Cosmopolitan issues. While Cosmopolitan featured a total of 996 advertisements (an average of 83 advertisements per issue), the $G Q$ issues feature 564 advertisements (an average of 47 advertisements per issue).

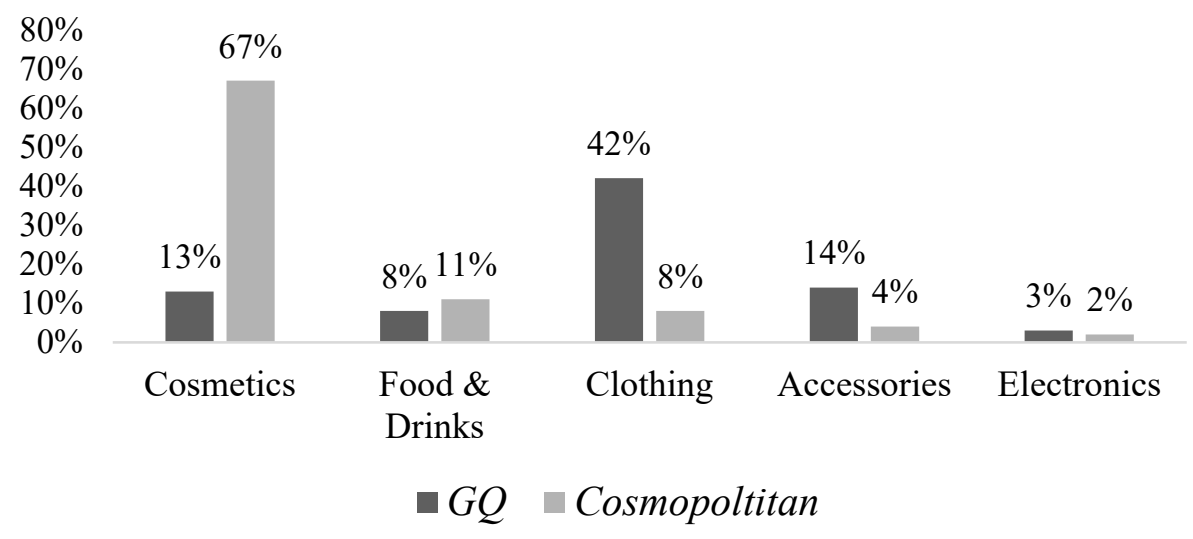

Figure 5: Frequencies of product groups advertised in $G Q$ and Cosmopolitan. 
As expected, the categories of the advertised products differ between the two magazines. The top three categories in Cosmopolitan were 'beauty products,' 'hair care,' and 'skin care.' Besides those categories, there were two more categories ('perfume,' 'razors') pertaining to cosmetic products. Except for 'skin care' and 'perfume,' the selected $G Q$ issues do not contain any of the aforementioned categories (cf. Figure 5).

Combining all the categories related to cosmetic products, 67 percent of the all the products advertised are cosmetic products. The category of 'cosmetics' in $G Q$, however, is only represented by 13 percent. This already draws a direct connection to the findings presented in Section 4 . Adjectives which refer to bodily imperfection and "which need to be improved by the product in order to construct a better identity" (Meyn/Schröder/ Verthein 63) do not seem to be of importance for the predominantly male readership of $G Q$ magazine. Four more product categories can be found both in in Cosmopolitan and GQ: 'food \& drinks,' 'clothing,' 'accessories,' and 'electronics' (cf. Figure 6). What might be noteworthy with respect to this is the large distribution of 'clothing' - 42 percent in $G Q$, but only 8 percent in Cosmopolitan.

Comparing the two corpora (cf. Figure 6), the categories 'material quality' and 'personal quality' stick out. 'Material quality' adjectives, hence adjectives that qualify the product, are used more often when a male readership is addressed ( $43.6 \%$ in $G Q$ as opposed to $28 \%$ in Cosmopolitan). This establishes a connection to the claim that men concentrate on the primary message of an advertisement (cf. Sheehan 2014: 90). The product, which is at the center of interest for the male reader, is described - hence, this information will be processed by the reader. However, targeting a female readership, the strategy is to directly refer to the female addressee with 'personal quality' adjectives (12.60\% in Cosmopolitan as opposed to $2.6 \%$ in GQ; cf. Meyn/Schröder/Verthein 55). 


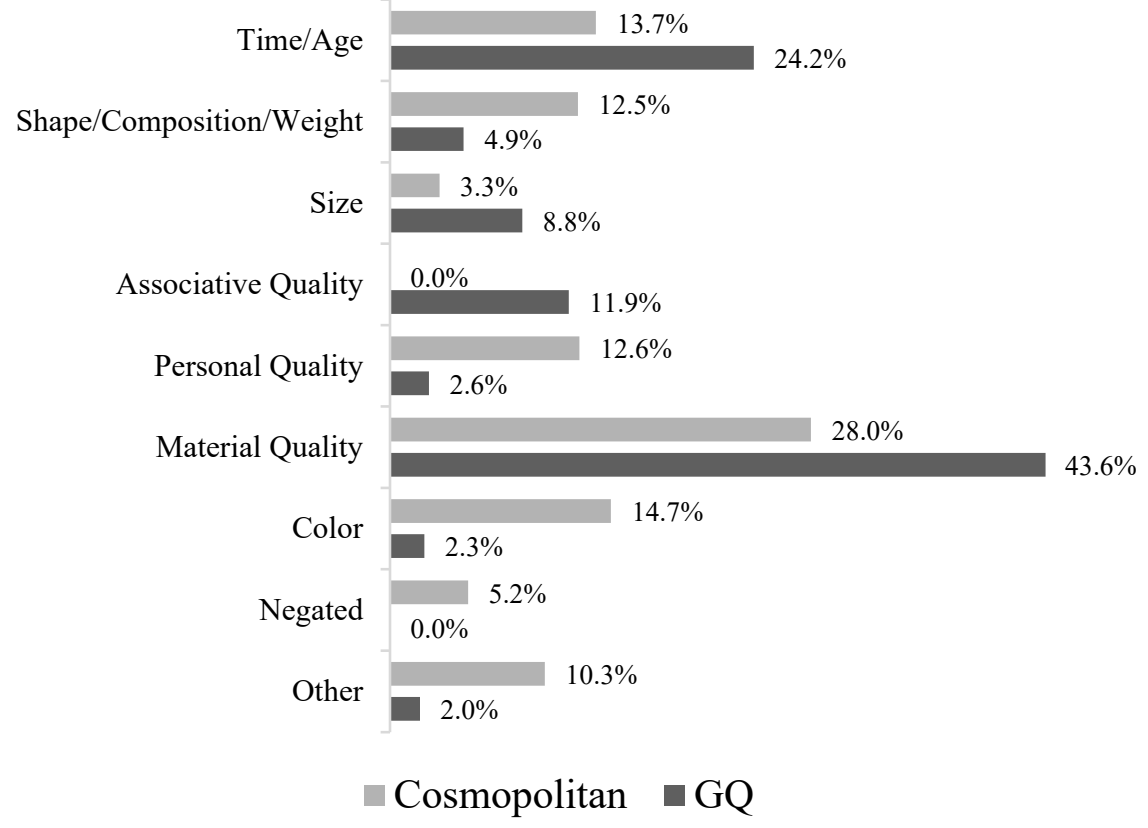

Figure 6: Frequency of adjectives per category in $G Q$ vs. Cosmopolitan advertisements

Furthermore, one of the major differences is the category of 'negated' adjectives that is not present in the $G Q$ Adjective Corpus at all. Nevertheless, there were a considerable number of adjectives with 5.2 percent to be found in the Cosmopolitan Adjective Corpus. They support the strategy of presenting the consumer with an imperfect image of the woman which can only be altered through the purchase of their product (cf. Meyn/Schröder/Verthein 61). Clearly, the identity of males is not referred to with the help of 'negated' adjectives. Moreover, the absence of 'negated' adjectives proves an overall positive approach when addressing men (cf. Sternkopf 209). Self-expression does, however, play a role in the category of 'associative quality,' which is not represented in Cosmopolitan, but with 11.90 percent quite prominent in $G Q$. This category is concerned with the identity of men through the use of adjectives which refer to a distinct consumer lifestyle (cf. Kornberger 191). While the advertisers attach a 
certain lifestyle to their products via the use of 'associative quality' adjectives targeting men (self-determined, cool, speakeasy-inspired), the advertisers do also attach emotions to their products, which was illustrated by the use of 'color' adjectives targeting at women (First Date at the Golden Gate, Kiss me at Midnight).

In conclusion, three major differences were detected by comparing the two studies. First, while the Cosmopolitan Adjective Corpus revealed the use of adjectives referring to the addressee, the use of adjectives in $G Q$ demonstrated a greater use of adjectives referring directly to the product. Secondly, the absence of 'negated' adjectives revealed an overall positive attitude of the advertisers when men are being addressed. On the contrary, women are approached with 'negated' adjectives in order to draw an imperfect picture of their identity. The third major difference is connected to identity construction. Advertisers address males by attaching a lifestyle, as part of their identity, however, they attach emotions to the product when they want to attract the interest of women.

\section{CONCLUSIONS}

The contrast between the distribution of adjectives in $G Q$ and Cosmopolitan magazine with regard to the respective adjective categories resulted in the revelation of three major advertising strategies aiming at men. Through this analysis, the first two research questions are answered:

1. Which specific strategies are used in $G Q$ Magazine advertisements?

2. How are the strategies reflected in the use of adjectives?

Firstly, advertisers avoid any trace of negativity when promoting a distinct product. In other words, a positive mind-set in the advertisement is crucial to persuade potential customers into buying a product. This claim is mainly backed up by the fact that the $G Q$ corpus did not contain a single negated adjective. What is more, is the large number of material quality adjectives, which all shed a positive light on the advertised good. Hence, positivity is a highly influential factor on males' consumer behavior.

Another striking finding is the attachment of a distinct lifestyle to a product. The results show that advertising campaigns shift their focus from simply aligning qualitative facts of products, towards constructing a lifestyle surrounding it. In the material, lifestyle-oriented adjectives with no direct link to the product itself were far more frequently employed than 'personal quality' adjectives. Thus, 
enumerating merits for the potential customers played a subordinate role compared to selling a lifestyle.

The last strategy concerns the hypothesis of men being linear thinkers. According to Sheehan (2014) advertisements need to provide men with simplistic and straight-forward messages to attract their attention. The material does underline this hypothesis to a certain extent, since most adjectives described the 'material quality' of an advertisement, hinting at the importance of factual information for the male addressee. Nonetheless, the data also revealed the employment of non-linear approaches when targeting a male audience. The construction of a distinct lifestyle that embeds the product into the consumer's life is not a merely factual approach. In conclusion, the hypothesis for the scope of the corpus cannot be verified.

Moving on to the third research question: Are men and women addressed in different ways by the use of adjectives? Comparing both studies confirmed the emergence of gender-specific features. For once, advertisements in Cosmopolitan include a large quantity of color-adjectives, which are foremost used to convey emotions and tie them to the product. Moreover, advertisements targeting women also arouse a need for a single product by pretending female customers are in a state of imperfection, hence appealing to their inner drive to reverse it. Accordingly, the products' effects on the addressee reflected in the adjective category 'personal quality,' ought to trick women into buying a product to improve themselves.

Additionally, the comparison of advertised goods in both magazines uncovered gender-oriented product groups. Despite the discovery of five matching groups, others are exclusively addressed in either one of the magazines. While household supplies are only advertised in Cosmopolitan, financial products cars, $G Q$ self-marketing, TV, and media are targeting men in $G Q$ magazine.

All in all, this study contributes to the identification of gender differences in advertising strategies, product groups and the use of adjectives from a sociolinguistic perspective which mainly focuses on gender. Hopefully, this research project is a starting point for future investigations of gendered language in advertising. Other interesting additions might include the role of rhetorical devices and collocations.

\section{Works Cited}

Behnam, Biook and Jafar Zamanian. "Gender and the Discourse of Advertising in English and Persian Magazine Advertisements" International Journal of Academic Research in Business and Social Sciences, 4.11 (2014): 1-9. 
Belk, Russell. "Are we what we own?" April L. Benson (ed.) I Shop, Therefore I Am: Compulsive Buying and the Search for Self. Lanham: Jason Aronson, 2000. 76-97.

Blöhdorn, Lars M. Postmodifying Adjectives in English. An Integrated Corpus-Based Approach. Frankfurt am Main: Peter Lang, 2009.

Coates, Jennifer. Women, Men and Language: A Sociolinguistic Account of Gender Differences in Language. New York: Routledge, 2016.

Haas, Adelaide. "Male and Female Spoken Language Differences: Stereotypes and Evidence." Psychological Bulletin. 86.3 (1979): 616-626.

Harper, Savannah. The Masculinity Masquerade: The Portrayal of Men in Modern Advertisement. The University of North Texas, 2013.

Hesse-Biber, Sharlene Nagy. Mixed Methods Research: Merging Theory with Practice. New York: Guilford Press, 2010.

Hoyer, Wayne D. MacInnis, Deborah J. and Rik Pieters. Consumer Behavior. Boston: Cencage Learning, 2016.

Ingwer, Mark. Why Marketers Must Understand Consumers' Need for Self-Expression. $<$ http://www.brandingmagazine.com/2014/07/01/why-marketers-mustunderstand-consumers-needs-for-self-expression/> (03/21/2017).

Ingwer, Mark. Empathetic Marketing. How to Satisfy the Six Core Emotional Needs of Your Customers. New York. Palgrave Macmillan, 2012.

Katz, Helen E. The Media Handbook: A Complete Guide to Advertising Media Selection, Planning, Research, and Buying. 2nd ed. New Jersey: Lawrence Erlbaum Associates, Inc., 2003.

Kornberger, Martin. Brand Society. How Brands Transform Management and Lifestyle. Cambridge: Cambridge University Press., 2010.

Leech, Geoffrey N. English in Advertising. London: Longman, 1966.

Leiss, William. Social Communication in Advertising: Consumption in the Mediated Marketplace. New York: Routledge, 2005.

Mayring, Philipp. Qualitative Inhaltsanalyse: Grundlagen und Techniken. Beltz Verlag: Weinheim \& Basel, 2010.

Meyn, Sabrina; Schröder, Mattis and Susanne Verthein. "When 'Kook-a-Mango' and 'First Date at the Golden Gate' Become Colors: Gender-Specific Adjectives in Current Print Advertisements." Lars M. Blöhdorn, and Jannike K. Schwarten. (eds.) Signaling Identity Through Discourse: Cultural Impacts on the English Language. Hamburg: Kovac, 2015. 47-67.

Paradis, Carita. Degree Modifiers of Adjectives in Spoken British English. Lund: Lund University Press, 1997.

Rohde, Deborah. The Beauty Bias. The Injustice of Appearance in Life and Law. Oxford. CUP, 2010.

Sheehan, Kim B. Controversies in Contemporary Advertising. Thousand Oaks: Sage, 2014

Sternkopf, Sylvia-Michèle. Language and Business. International Communication Strategies in Saxon Small and Medium-Sized Companies. Norderstedt: Diplomica Verlag, 2004.

Swann, Joan. Girls, Boys \& Language. Oxford: Blackwell Publishers, 1992. 
Vestergaard, Torben and Kim Schrøder. The Language of Advertising. Oxford: Blackwell Publishers, 1995.

\section{BIONOTES}

LARS M. BLÖHDORN, Ph.D., is Assistant Professor of English at Kiel University, Germany, his alma mater, from which he received an M.A. in 2002 and a Ph.D. in 2008. With more than 20 monographs in 4 languages, he has published widely in the area of Cultural Semantics, Syntax, and English Language Teaching, and has recently presented several papers at international conferences in Germany, Romania, the Ukraine, and Russia. As an author and translator, he has additionally specialized in the fields of Finance and Life Sciences, having published for the largest and most renowned medical centers, such as the Charité in Berlin, Germany.

SABRINA MEYN-KRUSE holds an M.A. degree in English and American Literatures, Cultures, and Media as well as an M.Ed. degree in English and Physical Education from Kiel University, Germany. She currently teaches English, German, and Physical Education at a vocational school in Neumünster, Germany.

NADJA LINKE graduated from Kiel University, Germany, with M.A. degrees in Media Science and International Comparative Sociology as well as English and American Literatures, Cultures, and Media. After her graduation, she worked as an External Communication specialist for UNICEF Cambodia in Phnom Penh and Common Cause in Washington D.C., before starting her position as a Public Information Officer at the German Adult Education Association in Bonn, Germany. 